\title{
The Solar Dynamics Observatory (SDO) Education and Outreach (E/PO) Program: Changing Perceptions One Program at a Time
}

\author{
E. Drobnes • A. Littleton • W.D. Pesnell • K. Beck • S. Buhr • R. Durscher • S. Hill • \\ M. McCaffrey • D.E. McKenzie · D. Myers • D. Scherrer • M. Wawro • A. Wolt
}

Received: 13 January 2010 / Accepted: 30 November 2011 / Published online: 21 December 2011

(C) The Author(s) 2011. This article is published with open access at Springerlink.com

\begin{abstract}
We outline the context and overall philosophy for the combined Solar Dynamics Observatory (SDO) Education and Public Outreach (E/PO) program, present a brief overview of all SDO E/PO programs along with more detailed highlights of a few key programs, followed by a review of our results to date, conclude a summary of the successes, failures, and lessons learned, which future missions can use as a guide, while incorporating their own content to enhance the public's knowledge and appreciation of science and technology as well as its benefit to society.
\end{abstract}

Keywords Solar dynamics observatory · Education and public outreach

The Solar Dynamics Observatory

Guest Editors: W. Dean Pesnell, Phillip C. Chamberlin, and Barbara J. Thompson

E. Drobnes $(\varangle) \cdot$ A. Littleton · D. Myers · M. Wawro · A. Wolt

ADNET Systems Inc., Greenbelt, MD 20771, USA

e-mail: emilie.drobnes@nasa.gov

E. Drobnes $(\bowtie)$

e-mail: emilie.drobnes@gmail.com

W.D. Pesnell

NASA Goddard Space Flight Center, Greenbelt, MD 20771, USA

S. Buhr · M. McCaffrey

The Cooperative Institute for Research in Environmental Sciences (CIRES), Boulder, CO 80309, USA

K. Beck

Stanford University Haas Center for Public Service, Stanford, CA 94305, USA

R. Durscher · D. Scherrer

Stanford University, Stanford, CA 94305, USA

S. Hill

RS Information Systems, Lexington Park, MD 20653, USA

D.E. McKenzie

Montana State University, Bozeman, MT 59717, USA 


\section{Introduction}

We present an overview of the education and public outreach (E/PO) program associated with the Solar Dynamics Observatory (SDO) mission. Reflecting on our efforts leading up to launch, we will provide insight into the programs developed, the lessons learned, and provide a model for future missions to build upon.

Many stakeholders (NASA, Department of Education, National Research Council, etc.) understand the inherent value of embedding E/PO programs into missions and scientificresearch environments. The close connection to the science and data, coupled with the cooperation between scientists and education specialists, is imperative to successful engagement of the public and fostering their curiosity (NRC, 2011). NASA and the Heliophysics Science Division (HSD) have responded by making E/PO an integral part of every science mission.

In this section, we begin by presenting the state of science literacy and education in the United States and how NASA and the HSD at NASA are choosing to address needs for improving science education.

\subsection{US Ranking in Science, Technology, Engineering, and Mathematics}

For the past decade, US pre-college students have trailed their peers in other countries in their literacy levels and science and math scores. A recent Organization for Economic Cooperation and Development (OECD) report showed that the US ranked 31st in mathematics performance and 23rd in science in a major study of 65 countries (OECD, 2011). The resulting low numbers of US students pursuing science, technology, engineering, and mathematics (STEM) higher-education degrees means having to fill the US STEM-related workforce needs externally. In response, and to fill its own STEM workforce needs, NASA has identified $\mathrm{E} / \mathrm{PO}$ as one of its priorities.

\subsection{The NASA E/PO Umbrella}

The NASA E/PO umbrella is continually evolving, often changing its approach and focus. However, the fundamentals tend to remain the same.

NASA has three main education goals: $i$ ) strengthen NASA and the nation's future workforce, $i$ ) attract and retain students in science, technology, engineering, and math (STEM) disciplines, and iii) engage Americans in NASA's mission (NASA Office of Education, 2007).

NASA's Strategic Framework describes four main areas of E/PO (NASA, 2007):

i) Higher Education: targets undergraduate and graduate students inside and outside of the classroom.

ii) Formal Education: targets the K-12 system and involves standards-based (National Science Education Standards, 1996) curricula.

iii) Informal Education: involves science-education settings outside the classroom and is not tied to the National Science Education Standards.

iv) Public Outreach: includes activities aimed at reaching audiences in their own environments and providing unique opportunities for interacting with significantly larger audiences.

In an effort to support this strategic framework, NASA requires missions to spend a percentage of their total cost on E/PO programs closely tied to its mission. In the past, this 
Table 1 SDO E/PO team and institutions

\begin{tabular}{|c|c|c|c|c|}
\hline Institution & AIA & EVE & HMI & Mission \\
\hline $\begin{array}{l}\text { Laboratory for Atmospheric and Space Physics } \\
\text { (LASP), Cooperative Institute for Environmental } \\
\text { Science (CIRES) }\end{array}$ & & Lead & & \\
\hline Goddard Space Flight Center (GSFC) & & & & Lead \\
\hline $\begin{array}{l}\text { Harvard-Smithsonian Center for Astrophysics } \\
\text { (CfA) }\end{array}$ & $x$ & & & \\
\hline $\begin{array}{l}\text { Lockheed Martin Solar and Astrophysics } \\
\text { Laboratory (LMSAL) }\end{array}$ & $\times$ & & & \\
\hline Montana State University (MSU) & Lead & & & \\
\hline Stanford University & $\times$ & & Lead & \\
\hline
\end{tabular}

Consultant-authors were associated with GSFC.

amount has varied between $0.5 \%$ and $2 \%$. The standard now is about $1 \%$ (SMD Science Management Council, 2010). This close link between missions and E/PO programs also helps ensure a tight connection between scientists, engineers, and the education community.

\subsection{E/PO Within the Heliophysics Science Division}

As part of the Living With a Star (LWS) program of the HSD at NASA, SDO must also align itself with the HSD E/PO goals and strategic communication objectives outlined within the Heliophysics Roadmap that builds upon the framework identified above. As is true with all science divisions, HSD sees E/PO as a key component of all flight and research programs (Christensen et al., 2009). However, with HSD science in mind, it highly encourages a more integrated set of activities that reflect the system-wide approach to HSD science and how we study the Sun and its effects on the solar system. The four strategic communication objectives as outlined in the roadmap are:

i) Seek opportunities to increase and maintain public awareness of heliophysics science through activities, materials, and events.

ii) Engage students and sustain their interest in heliophysics-related STEM subjects.

iii) Collaborate with and engage educators to enhance their knowledge of heliophysicsrelated subjects and activities.

iv) Build awareness among students, educators, and the public of the diverse range of career opportunities related to heliophysics science and missions.

\section{SDO Education and Public Outreach}

Building upon the work and experience of previous solar missions (SOHO, STEREO, and Yohkoh) and in keeping with the NASA Framework, the strategic communications objectives, and the system-wide approach outlined in the heliophysics roadmap, the SDO E/PO team (Table 1) has developed an overall approach and philosophy by which it has built its portfolio of programs. In this section we will discuss our program strategies, provide a brief overview of our portfolio of programs, and conclude with a more in detail highlight of a select few of our programs. 


\subsection{SDO E/PO Overall Approach and Philosophy}

Our guiding principles include $i$ ) using current educational research and best-practices approach regarding how people learn, $i$ ) addressing misconceptions and changing the perceptions and behaviors of target audiences, iii) developing programs that can serve as backbones to other missions and partners, $i v$ ) relying on extensive evaluation, and $v$ ) thinking outside the box. We will now expand on each of these.

We develop our programs using current pedagogy and research into "How People Learn" (Bransford, Brown, and Cocking, 1999) and how best to integrate inquiry into every experience. Inquiry refers to participant activities that help develop the knowledge and understanding of scientific ideas, as well as an understanding of how scientists study the natural world (National Science Education Standards, 1996). Our research guided us to move away from teacher/moderator-centered resources (a model where teachers/moderators lecture to students/participants or run very scripted activities) and to rely instead on learner-centered resources, which are fundamental to effective learning experiences at all ages and levels.

Efforts within the SDO E/PO program aim to improve people's perceptions and behaviors toward science and scientists. We want to change the common misconceptions that all scientists are, “. . white males ... who work alone in a laboratory ..." (Barman et al., 1997), "eccentric" (McAdam, 1990), and that science is hard. We have found that the best approach to changing these perceptions is to help scientists connect their work and research with educators and the public. We do so by designing programs that make science more approachable and provide multiple opportunities for audiences to meet and interact with a variety of scientists and engineers. These experiences slowly break down the public's false perceptions of scientists and make science more accessible. In doing so, we also encourage a change in audience behaviors. Families are encouraged to participate in more science-related activities outside the classroom and our programs.

Programs are developed to serve as models or backbones. This approach provides two benefits: $i$ ) it allows for the development of big-picture programs and $i$ ) allows other missions and institutions to easily plug into or adapt the program model to their own needs. This big-picture approach to program development aligns with the heliophysics roadmap desire to build E/PO programs that reflect the system-wide approach to heliophysics science and ensures the public is able to more easily connect to our story and science. The plug-in model helps ensure sustainability of programs long after missions or small funding sources have run out.

Although only a small percentage of resources was allocated to evaluate our programs, some form of evaluation was applied at all stages of the development cycle. Some programs have had a much more rigorous evaluation than others. An increased percentage of funds $(20 \%-30 \%$ of cost) have been allocated for evaluation of all post-launch efforts. This will provide us with the tools necessary to understand the effectiveness and impact of our current and future programs.

The SDO E/PO team strives to find new and innovative ways to reach out and share the excitement of the mission with a broad range of audiences. This includes exploring unexpected venues such as the "Did You Know" campaign that placed science factoids on the back of bathroom stalls and drink coasters as well as using social-media programs such as Facebook ${ }^{\mathrm{TM}}$ and Twitter ${ }^{\mathrm{TM}}$ to create a personality for the mission. Team members interact daily with followers to build a strong open and active dialogue with the public.

\subsection{SDO E/PO Portfolio Overview - Higher Education}

The HMI "Space Weather Monitor" program provides authentic space-science instruments and hands-on access to data to students in early university years (more below). A more 
sensitive research-quality monitor that tracks solar and lightning-induced changes in the ionosphere is available for upper level and graduate programs.

The AIA "Montana Space Public Outreach Team (SPOT)" program trains college students from a variety of disciplines in how to present the latest discoveries in space science and are then dispatched to schools and community organizations around the state of Montana.

The HMI and AIA "Science in Service" program aims to instill in college students the necessity for performing public service no matter what their future profession might be. Students from a variety of disciplines are trained in how to be effective science communicators and then connect them to youths in San Francisco Bay Area communities through science mentorship and after-school science clubs.

\subsection{SDO E/PO Portfolio Overview - K-12}

The GSFC "A Day at Goddard” field trip brings high-school (students aged 14 - 18) physics classes to Goddard for a day consisting of a facilities tour, a high-tech classroom laboratory experience, and a career-oriented meet-and-greet with scientists and engineers.

The GSFC "Think Scientifically" is a story-based science-literature series that integrates a classic storybook format with fundamental science to make an educational product that can be easily integrated into elementary-school (students aged 5-10) classrooms.

The GSFC "SDO Ambassador" program connects SDO scientists, engineers, and E/PO staff with teachers in the Washington, DC metropolitan area. SDO Ambassadors visit K-12 (students aged 5-18) classrooms for a day to present SDO, participate in a question and answer session, and conduct an SDO-related hands-on activity.

The GSFC, Atmospheric Imaging Assembly (AIA), Helioseismic and Magnetic Imager (HMI), and EUV Variability Experiment (EVE) "SDO Teacher's Guides" are a comprehensive set of solar- and space-weather-related activities developed for use in middle (students aged $11-13$ ) and high-school (students aged 14-18) level classes.

The EVE "Solar Science Learning Kit" and associated Teacher Workshops were developed to support high-school (students aged 14-18) science courses. They include a collection of materials developed by the SDO E/PO team to bring solar and space-weather content into the classroom within the educational standards all teachers must follow.

The HMI "Sudden Ionospheric Disturbance (SID) Monitors" are part of the "Space Weather Monitor" program noted above and were designed to give students access to authentic research equipment, experiences, and data. The low-cost, high-school (students aged $14-18$ ) version of the monitor allows students to track solar-induced changes in the ionosphere.

The AIA "Challenger Learning Center (CLC) Module Update" program integrated a space-weather scenario into the "Return to the Moon" and "Voyage to Mars" missions. During the simulated missions, students receive a coronal mass ejection alert from the SDO satellite. In determining if the event is headed towards them, students learn about the magnetosphere, space weather, and solar activity.

\subsection{SDO E/PO Portfolio Overview - Informal Education}

The GSFC "Family Science Night (FSN)" program is designed for middle-school children (children aged 11-13) and their families. Families explore space-science themes through a series of monthly two-hour events aimed at building their awareness of the importance of science in their daily lives. 


\subsection{SDO E/PO Portfolio Overview - Public Outreach}

The GSFC "Sunday Experiment" is a program for families with young children designed to provide easy access to age-appropriate science content through easy hands-on activities and an opportunity to meet scientists and engineers.

The GSFC "AstroZone and Exploration Station" are four-hour, free-to-the-public open houses, held in conjunction with professional science meetings. The programs offer a variety of easy, family-friendly, hands-on activities and an opportunity to interact one-on-one with scientists, engineers, and education specialist.

The EVE "Science Writers Workshop" held at the Laboratory for Atmospheric and Space Physics (LASP, Boulder, CO, USA) prior to the launch of SDO brought 13 journalists from print and new media together with SDO/EVE scientists. Workshop themes included: "The Anatomy of the Sun"; "Impact of the Solar Minimum on Climate and the Space Environment"; "What will Solar Max look like?"; "Implications for Studying the Sun and for Space Weather"; and "Looking to the Future: The Great Observatory".

The EVE "Video Series" includes an overview of the EVE instrument, a virtual tour of LASP, and an overview of various space-science careers. Scientists attending the abovedescribed Science Writers' Workshop were also interviewed about their solar-science research.

The GSFC and HMI "SDO Social Media" campaign is comprised of the SDO website, Twitter $^{\mathrm{TM}}$ feeds, Facebook ${ }^{\mathrm{TM}}$ fan pages, YouTube ${ }^{\mathrm{TM}}$ and Flickr ${ }^{\mathrm{TM}}$ channels, and several topic-specific blogs. Each effort has been strategically designed and aims to interact with key target audiences in unique and efficient ways helping the mission engage the public in an informal conversation and create a sense of community around the SDO mission. For more information visit http://sdo.gsfc.nasa.gov/ and click on the social-media tab to the right of the screen.

The GSFC "Did You Know" campaign focuses on reaching non-traditional audience in unexpected locations by providing solar- and space-weather-related factoids on signs placed on tables, the back of bathroom stalls, and drink coasters.

\subsection{SDO E/PO Portfolio Overview - Highlights}

The "Space Weather Monitor" program: Studies confirm that the best way to learn science is to do science (AAAS, 1993; Boyer Commission, 1998). Based on this premise, this program was designed to provide authentic, space-science instruments to students in high school and early university years. The US National Science Foundation (NSF) developed Sudden Ionospheric Disturbance (SID) monitors to detect changes to the Earth's ionosphere caused by solar flares. While design of the low-cost instruments had been completed, no formal assessments had been made, and the instruments did not come with sufficient teacher-preparation or supporting educational materials. The "Space Weather Monitor" program addressed this by forming a team of E/PO specialists and HMI scientists to develop and implement a fouryear test program.

The SID monitors function by tracking Very Low Frequency (VLF) radio transmissions as they bounce off the ionosphere. Solar activity dramatically affects the Total Electron Count (TEC) in the ionosphere and hence affects the refraction of the VLF waves. Students use the monitors to track VLF signal strength, directly related to TEC and the waves' bounce points. The monitors come preassembled, but students "buy in" by designing and building their own antenna. The systems then require a simple PC to record the data and an optional internet connection (where available) to share data. The package includes detailed 
teacher-training materials developed in partnership between the Stanford Solar Center and the Chabot Space and Science Center of Oakland, California, as well as an installation guide and research guide designed to train students to understand their data and encourage them to explore further research projects.

Year-1 $\beta$ testing consisted of placing instruments in three local (San Francisco Bay area) schools (two high schools and one community college) with a high percentage of underserved students. Teachers were given direct access to HMI scientists for questions and clarifications. SDO scientists and other volunteers served as mentors to schools that requested them.

Year-2 was dedicated to creating a centralized data site where SID users could upload their data and to the distribution of over 150 instruments to high schools and universities throughout the US and at selected sites around the world.

In Year-3, the program was picked up by the United Nations for use during the International Heliophysical Year (IHY) where instruments were distributed to about 50 countries with a focus on developing nations (Scherrer et al., 2008). The United Nations International Space Weather Initiative (IWSI) selected an enhanced version of the SID monitor as a participating program, and instruments continue to be distributed to universities worldwide. Data from the SID monitors have been tested for use in adjusting real-time models of the ionosphere.

In Year-4, the distribution and mentor mechanisms have been successfully handed off to the Society of Amateur Radio Astronomers (SARA) ensuring that the program continues in a self-sustaining manner.

The "Family Science Night (FSN)" program: Parents and families have the greatest influence on children's attitudes towards education and career choices. Research shows that when students have family members involved in their education, they show increased achievement: higher grades, and improved problem-solving and cognitive skills (Fan and Chen, 2001). Based on this result, we, in partnership with NASA's Astrophysics Science Division, developed the FSN program for middle school children and their families. Middle-schoolaged children were chosen since they are at an age where interest in science and math can be nurtured and when they are still willing to participate in programs with their families. This program was designed as an informal education program that allows for more flexibility in its content and approach, and a deeper parent-child interaction as it was out of school and not tied to the science-education standards.

During the FSN program, families explore space-science themes through a series of monthly two-hour events. Our goal is to raise awareness in participating families of the importance of science in their daily lives and changing the way that families think about science, within the program and beyond. We use NASA science content with a focus on processes and infuse SDO mission science and data into sessions whenever appropriate. We also provide unique opportunities for participants to interact with volunteer scientists and engineers. We provide parents professional development to help parents become effective facilitators of inquiry with their own families and offer opportunities for the children to become comfortable teaching their parents and working with them as peers. Finally, we encourage family science-related activities outside of the program.

Years 1-4 were dedicated to the pilot testing of the program and refining of all facilitator guide materials. Our focus has shifted to the dissemination of the program to various locations across the USA in the year since launch.

The "SDO Social Media" campaign: Through the use of social media, the SDO E/PO team is able to engage a much wider audience, as well as engaging more deeply with the audience, than is possible through traditional outlets such as press releases (Mayfield, 
2008). Elements of our new media plan include the use of online tools, such as Twitter ${ }^{\mathrm{TM}}$, Facebook $^{\mathrm{TM}}$, YouTube ${ }^{\mathrm{TM}}$, blogs, and the SDO website. These services allow not only for dissemination of information, but also for two-way interaction and the building of conversations, crucial to extended engagement of the public and community building.

The NASA_SDO and NASA_SDO_EDU Twitter ${ }^{\mathrm{TM}}$ accounts have opened a constant dialogue between members of the public (i.e. followers) and members of the SDO E/PO, science, and engineering teams. These accounts post information on SDO, the Sun, NASA, and interesting developments in the STEM community. Followers can ask questions, comment on postings, and interact with members of the SDO team on a one-on-one basis. During the launch of SDO and first-light-related events, Twitter ${ }^{\mathrm{TM}}$ was used to include thousands of people from across the globe in the experience. Fifteen on-site "Twitter Correspondents" were trained to be effective science communicators and interact with those thousands of followers. Our audience included students from Romania, Mexico, and Alaska, home schooled families in Florida and Georgia, and 30 independently hosted events (events organized by members of the public not officially affiliated with SDO) including one in Second Life. For both launch and first light, the term "Solar Dynamics Observatory" was a "trending topic" on Twitter ${ }^{\mathrm{TM}}$ for over 24 hours. Twitter ${ }^{\mathrm{TM}}$ defines a trending topic as those topics that are occupying the most people's attention on Twitter ${ }^{\mathrm{TM}}$ at any given time. It is important to note that most trending topics only last between 5-11 minutes and are generally associated with a celebrity or noteworthy news topic.

The Facebook ${ }^{\mathrm{TM}}$ page has an intentionally more playful approach with updates made in the first person, from the satellite's perspective. "Little SDO" (now turned into a fan page) interacts daily with its friends (such as Camilla Corona) and followers around the world and shares a wide variety of solar and space-related information. This approach was chosen to give a personality to the spacecraft and allow followers to connect to it in the same way viewers connected with Disney's Wall-E character.

The YouTube ${ }^{\mathrm{TM}}$ channels stream SDO movies in a format that the public is intimately familiar with, and allows the viewer to easily share videos that they find interesting with members of their social circle, while the SDO website provides the background and details of the mission and serves as a resource to the public. The website also provides the public with easy access to the data (images and movies) through a variety of developed browse tools.

The SDO mission mascot, Camilla Corona SDO, is also on various social-media outlets and assists with sharing sun- and space-weather updates, but also focuses on getting girls and boys excited about careers in science, technology, and engineering fields. It follows the more playful approach to connect people to the SDO mission.

\section{Results}

This section presents the results obtained for those programs that performed formal and informal evaluations. Formative assessment is performed throughout a program's development and provides feedback to developers on how to improve a program as it is built. Summative assessment is a final evaluation at the end of a project life to indicate if it has met its stated goals. Programs that were evaluated are discussed below. Evaluation efforts for the "Think Scientifically" book series, the "SDO Teacher's Guides", and various classroom resources including the EVE video series have not yet begun. We are awaiting the final results from the "Science Writers' Workshop". 


\subsection{The Space Weather Monitor Program (SID Monitors)}

Extensive formative assessment of this program and materials was done over the four-year study period, with significant involvement by SDO scientists. A California State University graduate student performed formal summative assessment of this program. Surveys were distributed to around 250 of the SID installations, with a 56\% response rate. Among other findings, $78 \%$ of respondents rated the program "highly effective" or better for teaching about solar activity, and $70 \%$ rated the program as "highly effective" or better in conducting a scientific investigation. Summative assessment revealed that about $50 \%$ of sites did experience "some difficulty" with installation. The "SID" program is now successfully selfsustaining. The Space Weather Monitor program was one of only two projects highlighted for commendation in the National Research Council's (NRC) report on the NASA E/PO program (Quinn et al., 2008)

\subsection{The SPOT Program}

A Ph.D. student from the Montana State University Education Department provides formal summative assessment of this program. Evaluation of this program focuses on the impact that presentations have on students and communities visited. The evaluator examines the teacher-submitted evaluations as well as the training and retention of student presenters via phone interviews. Although the K-12 students are not surveyed for their interest in the presentations, teachers are asked to describe the level of student interest, both during and after the "SPOT" presentations. The "SPOT" program has visited over 639 locations since it began to receive SDO funding in 2003. Almost three-quarters of the teachers surveyed commented that they could tell the students were interested because of the questions they were asking. This statement from a teacher is typical of these remarks: "Students asked many questions and were engaged during the program." Almost one quarter of the teachers indicated that their students continued to talk about the program after the presenters left.

\subsection{The Science in Service Program}

Formative assessment was carried out for each of the first four years of this program. Student participants and local community leaders were involved in evaluation discussions after each local visit, and also completed extensive questionnaires at the end of the term. The program was adjusted when weaknesses were identified. At the end of the fifth year, summative assessment was also carried out. The focus of the final evaluation was to determine whether the program was effective enough to warrant its funding and support by Stanford University. Extensive interviews were conducted, both with participants, involved HMI scientists, and local community leaders. A written report was generated, discussed, and evaluated. The final result of the assessment was that Stanford would assume responsibility for running the program and provide on-going funding to ensure its continuity. The successful program is now independent of SDO and self-sustaining.

\subsection{A Day at Goddard}

Magnolia Consulting is performing the ongoing formal evaluation of this program. Evaluation data collection activities for the "A Day At Goddard" field trips include student and teacher feedback surveys. Evaluators designed the student survey to capture students' perceptions of the field-trip components, and impacts on their interest and understanding of 
space-science and related careers. Evaluators designed the teacher survey to gather feedback from teachers on the event. Feedback included teachers' perceptions of impacts of the field trip on their students' awareness of careers, interest in space science, and understanding of the work of GSFC scientists and engineers. Initial results indicate that the events are effective at engaging student interest in space science and provided good exposure to the work of GSFC. Hands-on activities and interactions with scientists and engineers are particularly engaging for students. Four classes with a total of 52 students have participated in the program since evaluation began.

Student-survey results indicate that the program is successful in stimulating or maintaining interest in space-science and science careers for the majority of students who attended. $48 \%$ of students indicated that they were more interested in science careers as a result of the program while $21 \%$ indicated that interest was sustained. $54 \%$ of students also indicated that they were more interested in space science as a result of the program while $22 \%$ indicated that interest was sustained.

Teacher surveys found that $100 \%$ of teachers found that activities were effective in increasing students' understanding of the work at GSFC, that activities were effective in generating students' interest in space science, and that activities were effective in increasing students' awareness of STEM careers.

\subsection{SDO Ambassador}

Magnolia Consulting is performing the ongoing formal evaluation of this program. Datacollection activities for "SDO Ambassador" visits include teacher- and student-feedback surveys. Student-feedback surveys include Likert-scale (a scale that asks students to rate a question on a sliding scale usually $1-5$ ) items about their perceptions of the event and openended items about what they learned, what they liked best, and what they would change. Since evaluation of the program began, two schools with a total of five classrooms and 86 students have participated.

Of the respondents, $97.7 \%$ agreed or strongly agreed that they had fun learning about solar science and that they had learned new things about solar science from participating in the program. Ninety three percent agreed or strongly agreed that the event made solar science interesting while $87.2 \%$ indicated that they learned about the Solar Dynamics Observatory from participating.

\subsection{The Solar Science Learning Kit and SDO ESL Space Science Course}

The ATLAS Assessment and Research Center is conducting ongoing external evaluation of this program. The evaluator conducted interviews with five users of the "ESL Space Science Course." Interviews focused on perceived learning outcomes of students, fit with existing curriculum, ease of lesson implementation, organization, format and compatibility with state standards.

Results indicate that most lessons appear to be usable without major barriers for implementation and that content was viewed as meeting state standards. Concerns were expressed about the narrow range of content given the amount of time needed to complete lessons. Assessments were perceived as too long and lacking sufficient validity.

Lessons using the SID monitor were taught at three sites. Learning outcomes from these lessons (e.g. collection of real data, knowledge of content) were perceived as valuable and fitting with existing curriculum and standards. The logistical component of installing the SID monitor was perceived as somewhat burdensome and the amount of effort needed to install the system may not justify outcomes. 


\subsection{Family Science Night}

An external evaluator at the Rochester Institute of Technology, conducted the evaluation for this program. A mixed method approach was used to evaluate the "FSN" program. Tools evaluated whether the program raised the awareness in middle-school children and their families of the importance of STEM in their daily lives, if the program enabled all members of a family to engage in active learning both within and beyond the program, and if the program promoted connections between parents and children. Since its inception, over 120 families and 500 individual participants have attended one or more "FSN" sessions.

Initial data showed that the "FSN" program does indeed motivate families to learn science together. Session observations reveal that $100 \%$ of the families engaged in learning science together for at least some part of every session. Participants were observed to be actively engaged (fully participating in activities with their families) in learning for approximately $75 \%$ of the total time. Almost all participants $(90-100 \%)$, adults and children alike, were consistently able to state something new that they learned during each workshop as a result of the activities undertaken, and are able to relate what they learned to their everyday lives. "FSN" also promotes learning beyond the workshops. On average $90 \%$ of families report that they conducted STEM-related activities as a family between workshops as a result of the "FSN" program.

The "FSN" program received the 2008 Robert H. Goddard Award for Exceptional Achievement in Outreach.

\subsection{The Sunday Experiment}

"The Sunday Experiment" was handed off to the Goddard Visitor Center before formal evaluation could be conducted. However, it is important to note that one of its primary aims was to increase the public's awareness of Goddard in the local community by increasing the number of visitors that come to the Visitor Center. As a result of the program, the Goddard Visitor Center now sees between 250 and 1000 visitors during "The Sunday Experiment" program days as opposed to the 25 seen on other weekend days.

\subsection{AstroZone/Exploration Station}

Although there is no formal external evaluation of the "AstroZone" and "Exploration Station" events, participant cards have been collected along with demographic information and time spent at the event. These surveys help us to determine whether the stated objectives are being met. They measure levels of engagement, time spent at the event, as well as increased knowledge and interest in the available science topics and the potential for future interest in the STEM topics at the event.

More formal evaluation of the program started in the Fall of 2011. At the December 2010 Exploration Station, 119 participant cards and 68 participant evaluation forms were collected from an estimated 200-250 attendees. Feedback indicated that Exploration Station met or exceeded all of its stated objectives. The groups with children averaged 1.5 hours in the exhibit hall indicating a high level of engagement: over $75 \%$ of the respondents indicated that they had learned something new at the event and were able to express what it was. The majority of attendees also indicated there was a topic they were introduced to at the event that interested them to such an extent that they were "likely" to conduct further inquiry into that topic. The event also scored very high on overall enjoyment (4.5/5). 


\subsection{SDO Social-Media Campaign}

We are currently working on a more integrated and effective social-media evaluation strategy. Without a formal evaluation methodology, concrete insights into efficacy and impact are difficult at this time. However, statistics and numbers are available that can serve as indications of levels of success.

Twitter $^{\circledR}$ : As of March 2011 the @NASA_SDO Twitter ${ }^{\mathrm{TM}}$ feed has about 7000 followers with nearly 200 followers being added every month. When the account is put through many of the online Twitter ${ }^{\mathrm{TM}}$ analytics tools that look at the number of followers, interactions with followers, and overall popularity, it receives nearly perfect scores when being graded on use and shows up in the top $15 \%$ of Twitter ${ }^{\mathrm{TM}}$ accounts that have also been scored (twittergrader. com). The account has a consistent web influence Klout Score in the mid-50s out of 100, indicating that we "create content that is spread throughout [our] network and drives discussions". The Klout Score is the measurement of overall online influence. The scores range from 1 to 100 with higher scores representing a wider and stronger sphere of influence. Klout uses over 35 variables on Facebook ${ }^{\mathrm{TM}}$ and Twitter ${ }^{\mathrm{TM}}$ to measure True Reach, Amplification Probability, and Network Score (beta.klout.com).

Facebook $^{\circledR}$ : SDO has over 14000 followers between its Little SDO profile and Little SDO fan pages on Facebook ${ }^{\mathrm{TM}}$. Trends seem to indicate that the pages get upwards of 1000000 views a month and around 14000 comments per month to the information posted. It is also interesting to note that there are almost equal numbers of male and female followers. On average 55\% are male and $42 \%$ are female. It is assumed that the remaining missing percentage is due to the option in Facebook ${ }^{\mathrm{TM}}$ not to pick a gender.

YouTube $^{\circledR}$ : SDO has multiple YouTube ${ }^{\mathrm{TM}}$ channels with over 15000 subscribers and 3500000 total views between them.

\section{Discussion}

After significant evaluation, many programs have been shown to meet or exceed their stated desired outcomes. Those programs that have not been handed off to partner institutions will continue to operate and in most cases, useful insight was gained into how to improve each of the programs. Those that received more critical evaluation are described below and have been significantly overhauled accordingly and are awaiting the next round of evaluations. A small sub-set of programs is still scheduled for formal evaluations. However, informal evaluation and data collection of these programs still indicate that they are worth continuing and dedicating funds to formally evaluate each of them.

In response to the "Space Weather Program" (high-school SID monitors) evaluation where $50 \%$ of sites experienced "some difficulty" with installation, an even easier-to-install and less-expensive (US\$50) monitor, SuperSID, was developed along with the improvement of all support materials, and the addition of an official mentorship component. This new monitor is now included in the "Solar Science Learning Kit." The program, which now includes over 500 sites, continues to grow and has now been handed off to the Society of Amateur Radio Astronomers. There has also been increased interest in these instruments as ways to increase student interest in science in developing nations, and the instruments continue to be distributed through the United Nations ISWI.

"SPOT program" evaluation indicated a desire for more content and longer-term connections to the presentations. Because of the geography of Montana and the program's statewide reach, it is often difficult to return to locations more than once, or provide on-going support to those interested. As a result, it was decided to develop pre- and post-presentation 
classroom supporting materials. Teachers and communities receive a packet of materials in advance of a presentation and are provided extra resources upon completion of the presentation. There are also discussions of starting a SPOT presentation teacher-training workshop series.

The "Solar Science Learning Kit" was developed as curriculum support material for the "SDO ESL Space Science Course." Formal evaluation provided the following recommendations: modify the curriculum to make it more modular (e.g., make single lessons stand alone) and fit lessons so they can be used in after-school programs; standardize lesson format to more clearly emphasize objectives, materials, and information such as difficulty levels for each lesson, amount of time needed, and prior knowledge needed to complete lesson; and change assessments to shorter format and develop new questions. These changes have been made and the latest version of the Kit is being distributed through the Colorado Science Teachers Space Summit, the MESA program and via videoconferences through the NASA Digital Learning Network.

Evaluation results of the "FSN" program and four years of $\beta$ testing and evaluations have allowed the development of a quite comprehensive and effective facilitator guide and program. Although it had not been thought about at the start of the program, a significant number of children participants with minor to severe mental disabilities participated in the program. The majority of these had ADD, ADHD, or Asperger Syndrome. The program inherently allowed the smooth and complete integration of these children who were able to participate fully in the program. In fact, moderators did not become aware of these students until a few sessions had passed and their parents commented that this was the first program that allowed their children to be equals and about the positive outcomes it had on their attitudes and self-esteem. Because this was not a goal of the program, there was no formal capturing of this finding other than through anecdotal evidence provided by parents. Along with funds for evaluation, a portion of the funds have also been reserved for research into how families learn. There is little research currently available on how families learn. What research can be found indicates how important families are to children's learning. As such, the "FSN" program hopes to contribute to this knowledge base. Formal evaluation of the program including dissemination sites will be completed in 2011. Final results should be available in 2012.

Both "AstroZone" and "Exploration Station" suffer from low turnout both in attendees and exhibitors. The programs were developed based on the American Meteorological Society's (AMS) WeatherFest that sees between 4000 and 5000 visitors come through its activity exhibit hall the day before its annual meeting held each year in January. WeatherFest has three advantages: $i$ ) access to televised meteorological staff that spread the word, $i i$ ) a local organizing committee, and iii) complete buy-in from the larger parent organizations (AMS and National Oceanic and Atmospheric Administration). These three areas are lacking in our own event. Along with improving the relationships with the American Astronomical Society (AAS) and the American Geophysical Union (AGU) the main areas of evaluation-based improvement noted by both the attendees and the exhibitors were increasing the number of attendees and increasing the number and variety of exhibitors. This does not come as a surprise and feeds into the increased efforts for our advertising campaigns for next year. The WeatherFest model confirms the draw such programs have and our informal survey results indicate those who do participate are quite engaged in what the program offers. However, attendance numbers must dramatically increase over the next two years for this program to be worth continuing. Hence, the majority of the recommendations for improvement are to assist in creating a more effective advertising campaign targeted to our audience and to potential exhibitors for future event. 
Like most social-media efforts, the impact of the SDO social-media efforts is difficult to measure. This is compounded by the constantly changing use of individual methods and shifting sense of community. Funds were allocated to evaluate these efforts. The team is looking to work with partners to develop the best tools and solutions to more effectively use social media. It will probably take a team of computer scientists, psychologists, and evaluation specialists to truly understand the effectiveness and impact of our efforts. As some of our bigger programs ramp down, more efforts will be allocated to this issue.

\section{Summary}

The SDO E/PO team has designed a comprehensive and well-balanced portfolio of programs that serve target audiences in all four of NASA E/PO areas. All programs have also successfully aligned themselves with NASA and heliophysics goals and objectives while keeping within our guiding principles.

The success of our programs is due in part to a significant amount of research performed when developing each of them, looking into best practices, as well as what has been done before including what worked and did not work. Lessons learned are invaluable to any development process. As such, we have shared some of ours in this article and do so in more detail throughout many of the resources that we produce and any of the best-practices documents that we develop.

All programs are built to improve the perceptions and behaviors of target audiences. The SPOT and SIS programs teach science and non-science students to be better science communicators, changing not only their own perceptions and behaviors but also those of students who they reach. A Day at Goddard, SDO Ambassador, The Sunday Experiment, AstroZone, and Exploration Station are positively shifting participant interest in science through hands-on activities and one-on-one interactions with scientists and engineers, while FSN and the SDO ESL Space Science Course are significantly changing the perceptions and behaviors of participants through extensive sustained interaction.

Programs such as The Sunday Experiment, FSN, and A Day at Goddard were built to serve as models and backbone programs that others could plug into. The Sunday Experiment is a nine-month program that dedicates each monthly meeting to a different mission or engineering challenge. The program as a whole may cost up to US $\$ 50 \mathrm{~K}$ a year in salaries or one half person facilities, and materials. However, a mission could choose to sponsor an event within an ongoing program for as little as US\$1K. By having multiple missions participate, it also means that should one mission go away, the program is able to continue by finding new missions to participate. This is also the case for each of the other programs that allow for new content to be easily plugged into the format. Lunar and planetary sessions have already been developed for FSN, and three more astrophysics sessions are in the pipeline. Sustainability is also a big part of strategy, and multiple programs of ours are now self-sustaining beyond the SDO mission. The CLC Module Update, The Sunday Experiment, Science in Service, and the Space Weather Monitor programs have all been handed off to partner institutions and continue to be successfully run without financial support from the SDO mission.

Thinking outside the box and being able to imagine innovative and creative programs is extremely important to the SDO E/PO team. Through the SDO social-media campaign, the SDO E/PO team has played a key role in how NASA's use of social media has evolved, even hosting the first non-shuttle space-flight launch Tweet-up. Prior to SDO efforts, a few missions such as Suzaku and the Mars Rovers began blogging in the first person personifying 
the satellites and robots. Missions such as Hubble and the Lunar Reconnaissance Orbiter were also taking advantage of Facebook ${ }^{\mathrm{TM}}$ and Twitter $^{\mathrm{TM}}$. However, there was no dialogue created, simply missions posting information for the public to read. As we were strategizing, there seemed to be clear signals from the public that their true desire was to be actively engaged in discussions. Through the SDO Facebook ${ }^{\mathrm{TM}}$ and Twitter ${ }^{\mathrm{TM}}$ accounts, the E/PO team is actively engaging the public and has built a strong and dedicated following that lets us know within seconds when one of our many online tools is no longer working, serving as our own core of science communicators, and even participating in our events at volunteers.

Now that SDO has launched and terabytes of data are being beamed back to Earth daily, the SDO E/PO team will adjust its focus to include student and public engagement with SDO data. We will look at different ways to get data into the hands of students via inquiry-based projects and into the public sphere through social media, the press, and "citizen-science" data-analysis projects.

Acknowledgements The SDO E/PO team would like to acknowledge and thank all those who have helped and supported our many efforts. Their contributions of writing and editing text, participating in question and answer sessions, volunteering at events, giving presentations, helping develop instruments and programs, as well as supporting teachers and students at all levels, have been invaluable to our efforts.

Special thanks to Elizabeth Citrin and Rob Lilly of the SDO Project Team for their support of E/PO during the development of the observatory. We would like to acknowledge members of the Science Investigation Teams for their contributions to this program. These include Philip Scherrer (HMI), Alan Title, Ed Deluca, and Bruce Ward (AIA), and Tom Woods (EVE).

We would like to say a special thank you to all of our volunteers, including Christopher Anderson, Caitlin Bacha, Monica Bobra, Phillip Chamberlain, Yaireska ColladoVega, Carmel Conaty, Priya Desai, László I. Etesi, Andrew Ingles, Leigh Jaynes, Rivers Lamb, Barbara Lambert, Haruko Makatani, Ryan O. Milligan, John W. Mitchell, Kim Ross, Andrew Singh, Hao Thai, Barbara Thompson, Jonathan Verville, Peter Williams, C. Alex Young, and the many teachers and students involved with our programs.

Finally, we would like to thank Phillip Chamberlin, Steven Christe, László I. Etesi, Todd Hoeksema, Jack Ireland, and Philip Scherrer for their contributions in preparing this article and providing insight into how to improve it.

This work was supported, in part, by the Solar Dynamics Observatory Project and NASA Grants NNH08CD27C-ROSES and NNH09ZDA001N-EPOESS.

Open Access This article is distributed under the terms of the Creative Commons Attribution Noncommercial License which permits any noncommercial use, distribution, and reproduction in any medium, provided the original author(s) and source are credited.

\section{References}

American Association for the Advancement of Science: 1993, Benchmarks for Science Literacy: Project 2061, Oxford University Press, New York. http://www.project2061.org/publications/bsl/online/index.php? txtRef=\&txtURIOld=\%2Ftools\%2Fbenchol\%2Fbolframe.html.

Barman, C.R., Ostlund, K.L., Gatto, C.C., Halferty, M.: 1997, Fifth grade student's perceptions about scientists and how they study and use science, http://www.physics.ucsb.edu/ scipub/^2004/ StudentPerceptions.pdf.

Bransford, J.D., Brown, A.L., Cocking, R.R.: 1999, How People Learn: Brain, Mind, Experience, and School, National Academy Press, Washington.

Boyer Commission on Educating Undergraduates in the Research University: 1998, Reinventing Undergraduate Education: A Blueprint for America's Research Universities, State University of New York, New York. http://naples.cc.sunysb.edu/Pres/boyer.nsf.

Christensen, A., Spann, J., St. Cyr, O.C., Cummings, A., Heelis, R., Hill, F., Immel, T., Kasper, J., Kistler, L., Kuhn, J., Reeves, G., Schwadron, S., Solomon, S., Strangeway, R., Tarbell, T.: 2009, Heliophysics: The solar and space physics of a new era, NP-2009-08-76-MSFC, Huntsville.

Fan, X., Chen, M.: 2001, Parental involvement and students' academic achievement: a meta-analysis. Educ. Psychol. Rev. 13, 1-22. 
Mayfield, A.: 2008, What is social media?, iCrossing, http://www.icrossing.co.uk/fileadmin/uploads/eBooks/ What_is_Social_Media_iCrossing_ebook.pdf.

McAdam, J.E.: 1990, The persistent stereotype: children's images of scientists. Phys. Educ. 25, 102.

NASA Office of Education: 2007, Strategic Coordination Framework: A Portfolio Approach, NP-2007-01456-HQ, Washington, DC. http://www.nasa.gov/pdf/189101main_Education_Framework.pdf.

National Science Education Standards, National Research Council: 1996, http://www.nsta.org/publications/ nses.aspx.

NRC: 2011, Committee on the Planetary Science Decadal Survey, Space Studies Board, Division on Engineering and Physical Sciences: 2011, Vision and Voyages for Planetary Science in the Decade $2013-$ 2022, National Academy Press, Washington. http://www.nap.edu/catalog.php?record_id=13117\#toc.

OECD: 2011, Lessons from PISA for the United States, Strong Performers and Successful Reformers in Education, OECD, Paris. http://dx.doi.org/10.1787/9789264096660-en.

Quinn, H.R., Schweingruber, H.A., Feder, M.A. (eds.), Committee for the Review and Evaluation of NASA's Precollege Education Program, National Research Council: 2008, NASA's Elementary and Secondary Education Program, National Academy Press, Washington. http://www.nap.edu/catalog.php?record_id= 12081.

Scherrer, D., Cohen, M., Hoeksema, H., Inan, U., Mitchell, R., Scherrer, P.: 2008, Distributing space weather monitoring instruments and educational materials worldwide for the IHY 2007: The AWESOME and SID project. Adv. Space Res. 42, $1777-1785$.

SMD Science Management Council: 2010, Policy and Requirements for the Education and Public Outreach Programs of SMD Missions, Science Mission Directorate Policy, SMD Policy Document SPD-18, NASA, Washington, DC. http://science.nasa.gov/media/medialibrary/2011/04/13/SPD-18_ MissionEPOPolicy_TAGGED.pdf. 